\title{
CFD Modelling of a Centrifugal Compressor with Experimental Validation through Radial Diffuser Static Pressure Measurement
}

\author{
Brett Dewar (D), , Jonna Tiainen, ${ }^{3}$ Ahti Jaatinen-Värri, ${ }^{3}$ Mike Creamer, ${ }^{1}$ \\ Mariana Dotcheva, ${ }^{2}$ Jovana Radulovic, ${ }^{2}$ and James M. Buick $\left(^{2}{ }^{2}\right.$ \\ ${ }^{1}$ Business Edge, 6 Dragoon House, Hussar Court, Westside View, Waterlooville, Hants, PO7 7SF, UK \\ ${ }^{2}$ School of Mechanical and Design Engineering, University of Portsmouth, Anglesea Building, Portsmouth PO1 3DJ, UK \\ ${ }^{3}$ School of Energy Systems, LUT University, P.O. Box 20, FI-53851 Lappeenranta, Finland \\ Correspondence should be addressed to Brett Dewar; brettdewar1@gmail.com
}

Received 15 January 2019; Revised 10 April 2019; Accepted 15 April 2019; Published 19 May 2019

Academic Editor: Ryoichi Samuel Amano

Copyright (C) 2019 Brett Dewar et al. This is an open access article distributed under the Creative Commons Attribution License, which permits unrestricted use, distribution, and reproduction in any medium, provided the original work is properly cited.

\begin{abstract}
This paper compares experimental static pressure measurement with CFD simulation in a centrifugal compressor at 12 points through the diffuser. Three mass flow rates are selected, each for three operating speeds giving nine total operating conditions. The results show that the CFD model generally slightly underpredicts the static pressure value as compared to the experimental results. The discrepancy between experimental and numerical results ranges between $-8 \%$ and $+6 \%$ and is fairly consistent for a given operating condition, except for close to the blade trailing edge where the pressure variation is less regular and where the pressure is increasing most rapidly with radial position. In the consistent region, where the pressure gradient is low, the discrepancy is around two percent or less for simulations close to the design operating point. Away from the design operating point the errors increase up to approximately $5 \%$. The simulation results were also used to investigate the effect of the position (from the blade trailing edge) of the impeller-diffuser interface (a characteristic of the frozen rotor simulation approach). Here an optimal position for the interface was found to be $2 \%$ of the blade radius. This value gave improved agreement with the experimental result in the initial region of the diffuser up to a distance of approximately $10 \%$ of the radius. At greater distances the position of the interface became less important. The results also highlighted a change in the pressure along the spanwise direction close to the tips. A dip in the pressure, which was observed in the experimental results, was only observed in the simulations close to the shroud. Close to the hub the simulation results recorded a small local peak. The simulation approach was then applied to further study the flow characteristics by examining the full-field velocity and pressure contours in the impeller and diffuser regions to identify changes due to the different operating conditions.
\end{abstract}

\section{Introduction}

Centrifugal compressors are widely used in a range of applications including refrigeration and air conditioning, power generation, aeronautics, turbochargers, and the oil and gas industry; and their design is an important factor in the performance and efficiency of the systems in which they are incorporated. Thus the simulation of centrifugal compressors is becoming increasingly important and has been applied to investigate a range of phenomena such as noise generation $[1,2]$, tip clearance $[2,3]$, effect of volute and diffuser geometry $[4,5]$, compressor performance [6$8]$, and the flow field through the compressor $[9,10]$. An important aspect of developing a numerical model is the validation stage, which usually involves a comparison with experimental data. Typically, when evaluating centrifugal compressor performance, the characteristics of the flow are only measured in two places: upstream of the compressor inlet and downstream of the volute outlet.

In recent years, one of the major trends in centrifugal compressor research has been at off-design operating conditions. Both the widening of operating range and the efficiency at off-design operations have been extensively studied in recent years, as the efficiency requirements for different systems have been increasing. As the off-design operations is more important than previously and CFD is 
commonly used in different stages in the compressor design, the CFD accuracy at off-design conditions also becomes more important.

Out of the accumulation of a body of work, a number of common approaches have resulted in terms of CFD model settings with regard to turbulence models [11-14], interface settings $[4,6,7,9,15-17]$, and boundary conditions $[7,11,18]$. There are a number of turbulent models which can be applied in a RANS simulation. Gibson et al. [11] assessed the performance of different turbulence models for the numerical simulation of a centrifugal compressor. Simulations were performed using different models including the Spalart-Allmaras, SST, a modified SST approach (SSTCC), and a turbulent frequency formulated Reynolds stress model (RSM- $\omega)$. The results were compared to experimental data for the pressure and temperature ratios and velocity contours at the impeller exit. The results showed that while the SST-CC and RSM- $\omega$ performed well near surge, the SST was efficient and provided accurate results over the entire speed line range. Röyttä et al. [14] compared the SST model with a k- $\varepsilon$ model in a study into the effect of blade angle in a centrifugal compressor. They also found the SST model to give the most realistic results. The SST turbulence model is identified as the most appropriate choice for turbomachinery applications in Shah et al.s review [12] and has also been widely used in a range of centrifugal compressor simulations $[13,19]$. A full discussion of the SST model is given by Menter [20].

Another important consideration when modelling centrifugal compressors is simulating the interface between the rotating impeller region and the stationary inlet and diffuser. When performing a steady state simulation, the impeller region is simulated in a rotating frame of reference and the other regions are simulated in a stationary frame of reference. At the interface there are two approaches: the mixing plane, where quantities are averaged circumferentially at the interface, and the frozen rotor method, where pressure and velocity are transferred directly across the interface, with the circumferential velocity adjusted by the local blade speed [21]. The frozen rotor approach keeps the relative positions of the blades fixed and so the results are position-dependent. Despite this it has been shown [21] that for a vaneless diffuser the net difference between a frozen rotor and a mixing frame reference is minimal and the approach is frequently applied in centrifugal compressor simulation $[4,6,7,9,14-18,22$, 23].

The current body of literature for the purposes of CFD model validation, to the best of the author's knowledge, focuses only on the inlet and outlet characteristics of the flow, namely, static pressure or a quantity derived from it, such as in $[1,2,4,7,8,15,16]$. These works also often do not include the components between the diffuser exit and the experimental outlet sensor in their CFD model. Whilst this is adequate for most industrial performance analysis, it falls somewhat short for the purpose of fully verifying a CFD model. A study of the in-situ development of the flow through the diffuser allows for the evaluation of a computational model not just in terms of its final output at a single point, but also at intermediate stages through the impeller. This becomes

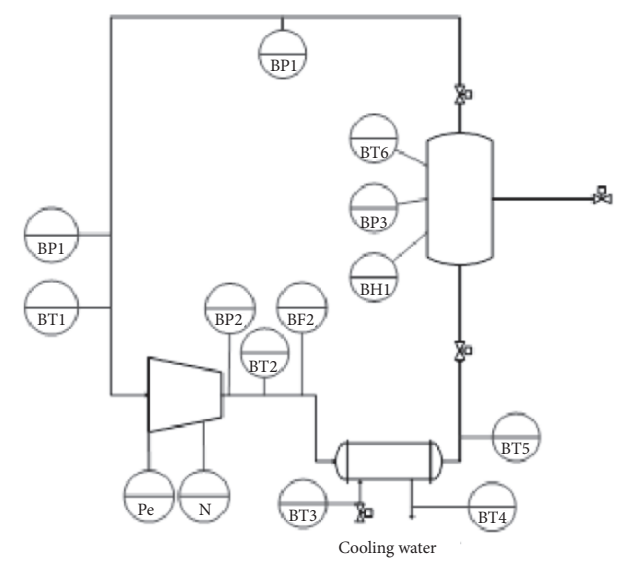

Figure 1: Process instrumentation chart. $B F$ flow, $B H$ humidity, $N$ rotational speed, $B P$ pressure, $P e$ electric power, and $B T$ temperature.

particularly important when assessing a model's validity as conditions move away from the design point.

Here we consider a CFD model validated against experimental pressure measurements at 12 points along the diffuser. The experimental and CFD details are set out in Sections 2 and 3 respectively. The results are presented in Section 4 in terms of the pressure ratios at the twelve measurement points, variations in the spanwise direction, the position of the frozen rotor interface, and the pressure and velocity fields in the inlet, impeller, and diffuser regions.

\section{Experimental Setup}

The test compressor is located in Laboratory of Fluid Dynamics, at Lappeenranta University of Technology, Finland. The compressor test facility is closed-loop, and the test compressor is a high-speed centrifugal compressor, controlled with active magnetic bearings. The impeller has nine full and nine splitter blades. The compressor is equipped with a parallel wall vaneless diffuser and a volute. The main design parameters are listed in Table 1, and the process instrumentation for the test stand is shown in Figure 1.

Air is taken from a settling tank, through an inlet valve. The flowrate, pressure, and temperature are measured before and after the compressor. After the outlet measurements, the airflow is cooled in a heat exchanger with water and transferred back into the tank through a control valve. The performance measurement setup and calculations comply with ISO 5389. The measured design operating point performance and uncertainties are shown in Table 2.

2.1. Static Pressure Measurements. Static pressures in the vaneless diffuser were measured at 12 different radial locations. The pressure taps were situated opposite to the volute tongue. Nine first pressure taps are on the shroud side, and the last three are on the hub side because of the volute. The pressure tap placement is shown in Figure 2 and summarized 
TABLE 1: The main design parameters.

\begin{tabular}{lc}
\hline Mass flow $[\mathrm{kg} / \mathrm{s}]$ & 1.8 \\
Specific speed $N_{\mathrm{s}}=\omega \sqrt{q_{\mathrm{v} 1}} / \Delta h_{\mathrm{s}}^{0.75}$ & 0.70 \\
Rotational speed $[1 / \mathrm{s}]$ & 461 \\
Impeller outlet radius $[\mathrm{mm}]$ & 271 \\
Diffuser outlet radius $[\mathrm{mm}]$ & 542 \\
\hline Blade backsweep at the impeller outlet [ $\left.{ }^{\circ}\right]$ & 40 \\
Blade height at the impeller exit [mm] & 12.2 \\
Diffuser height $[\mathrm{mm}]$ & 10.3 \\
Number of full and splitter blades & $9+9$ \\
\hline
\end{tabular}

TABLE 2: Design operating point performance.

\begin{tabular}{lcc}
\hline Parameter & Value & Relative error [\%] \\
\hline Total-to-total efficiency [\%] & 79.8 & \pm 0.81 \\
Total-to-total pressure ratio [-] & 2.36 & \pm 0.35 \\
Mass flow [kg/s] & 1.79 & \pm 0.54 \\
\hline
\end{tabular}

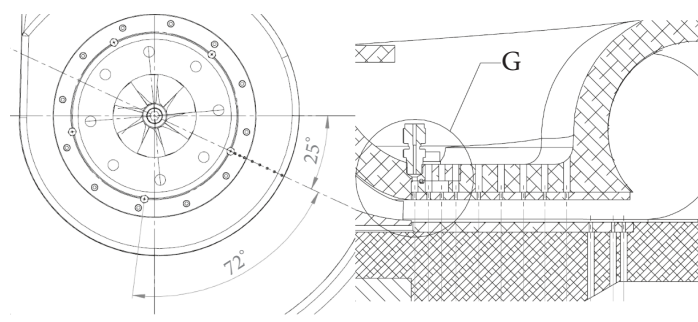

FIgURE 2: Pressure tap placement.

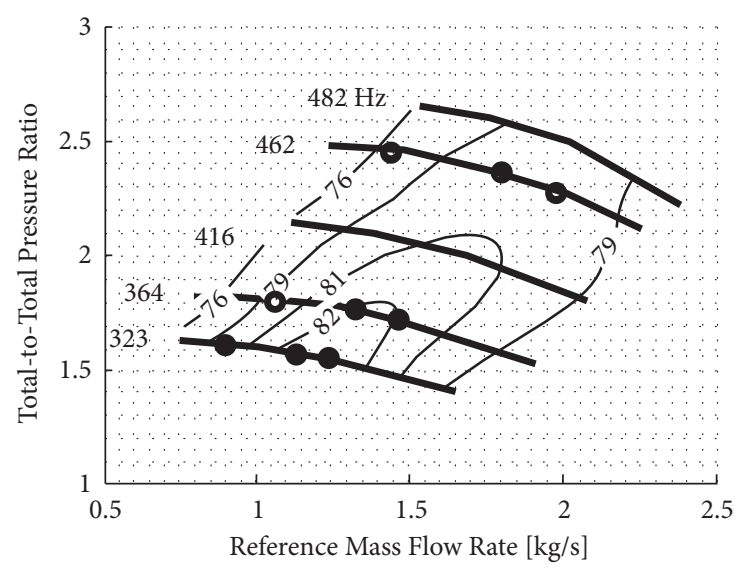

FIGURE 3: Compressor operating map and the operating points at which the static pressures were measured.

in Table 3. Trafag and Wika pressure transducers were used and the data collected with a Fluke Hydra data logger.

The static pressures were measured at nine different operating points. The nine points were at three different rotational speeds, three points at each speed line. The nine operating points are shown on the compressor operating map in Figure 3 and summarized in Table 4.

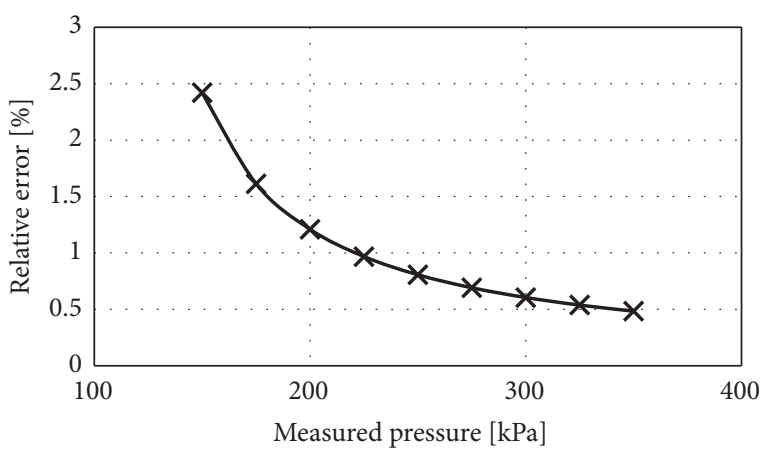

FIgURE 4: Measurement uncertainty for each static pressure measurement.

Once the desired operating point had been set, the compressor was let to run until all the temperatures had settled to a steady value. Once steady state had been achieved, the static pressures were recorded. Five pressure values were recorded for each location, and once the results were processed, the five values were averaged to give a single pressure for each location at each operating point. Figure 4 shows the relative error in the pressure measurements, which is the calibration error divided by the measured pressure. During calibration the average error for the range considered here was $0.4 \mathrm{kPa}$, however, the maximum error of $1.21 \mathrm{kPa}$ is used in Figure 4 .

\section{Numerical Study}

Simulations were carried out using commercial CFD software ANSYS CFX version 17.1 in steady state.

3.1. Domain Partition and Interface. Following $[4,6,7,9$, 15-17], the computational domain was partitioned into the stationary inlet, rotating impeller, and stationary diffuser with frozen rotor interfaces between adjacent domains. The 
TABle 3: Pressure tap locations.

\begin{tabular}{lccc}
\hline location & $r / r_{2}$ & location & $r / r_{2}$ \\
\hline 1 & 1.01 & 7 & 1.50 \\
2 & 1.07 & 8 & 1.59 \\
3 & 1.13 & 9 & 1.69 \\
4 & 1.20 & 10 & 1.80 \\
5 & 1.30 & 11 & 1.90 \\
6 & 1.40 & 12 & 1.95 \\
\hline
\end{tabular}

TABLE 4: Operating points at which the static pressures were measured.

\begin{tabular}{lccc}
\hline point & $N[1 / \mathrm{s}]$ & $q_{\mathrm{m}}[\mathrm{kg} / \mathrm{s}]$ & $\pi_{\mathrm{tt}}$ \\
\hline 1 & 461 & 1.98 & 2.28 \\
2 & 461 & 1.80 & 2.36 \\
3 & 461 & 1.44 & 2.48 \\
\hline 4 & 364 & 1.46 & 1.81 \\
5 & 364 & 1.33 & 1.72 \\
6 & 364 & 1.06 & 1.76 \\
\hline 7 & 323 & 1.24 & 1.54 \\
8 & 323 & 1.13 & 1.57 \\
9 & 323 & 0.90 & 1.61 \\
\hline
\end{tabular}

domain partitioning is shown in Figure 5. The rotational speed of the impeller domain was set to the desired speed.

3.2. Boundary Conditions. Total temperature and pressure were applied as inlet conditions with values of $96 \mathrm{kPa}\left(\mathrm{p}_{\mathrm{ref}}\right)$ and $300 \mathrm{~K}$, respectively. A mass flow rate outlet condition was used with values from Table 4 using a subsonic flow regime. Periodic boundary conditions were used between adjacent blade passages. This is the same approach as used in $[7,18]$.

The combination of a total pressure and temperature inlet with a mass flow rate outlet is the approach favoured for stability [11]. The hub and shroud for the inlet and diffuser domains, the hub for the impeller domain, and the blades themselves were set to wall (adiabatic, no slip, and smooth wall) boundary conditions. The shroud in the impeller domain was set as the same except the wall velocity option selected was "counter rotating wall".

3.3. Numerical Methods. Following [11-14] the k- $\omega$ SST model was selected. The chosen $\mathrm{k}-\omega$ SST model is widely used and has been validated for turbomachinery applications [20]. Recently, Gibson et al. [11] used the test case Radiver to demonstrate the differences between five turbulence models. They concluded that the k- $\omega$ SST model is reasonably robust to predict the basic local flow phenomena in the centrifugal compressor. The turbulence intensity was set at a medium intensity, $5 \%[3,11,24]$. The advection scheme and turbulence numerics were set to high resolution. Auto timescale, conservative length scale option, and a timescale factor of 1 were selected.
3.4. Mesh Convergence. The computational grid was generated in ANSYS Turbogrid and a convergence study is shown in Figure 6, and the final grid is shown in Figure 7.

The final mesh was the densest of those considered and consisted of approximately 2.2 million elements. The global size factor used was 1.75 and the near wall element size specification method was $\mathrm{y}+$ with a Reynolds number of $7 \times 10^{6}$ to give a target $\mathrm{y}+$ value of 0.5 . The passage spanwise blade distribution method selected was proportional with a factor set to 1 . Convergence was deemed sufficient when the RMS value of all the residuals reached $\mathrm{O}\left(10^{-5}\right)$. Following Celik et al. [25] a discretization error of $0.08 \%$ was found for the pressure ratio when the 1.06 million elements mesh was used.

\section{Results}

4.1. Pressure Ratios. A comparison of the experimental and simulated (area averaged) pressure ratios is presented in Figure 8 at each tapping position for each of the mass flow rates and rotational speeds considered. The first $9 \mathrm{CFD}$ results $\left(r / r_{2}<1.7\right)$ are at the shroud side and the three last at the hub side, in agreement with the experimental data. The percentage difference between the experimental and the simulations pressure ratios is also shown in Figure 8. Comparison of the results shows good general agreement between the experimental results and the simulations.

Away from the tips $\left(r / r_{2}>1.2\right)$ the differences remain somewhat constant. In this region the CFD results consistently underestimate the pressure ratio (ranging from virtually no underestimation to approximately 6\%) with respect 


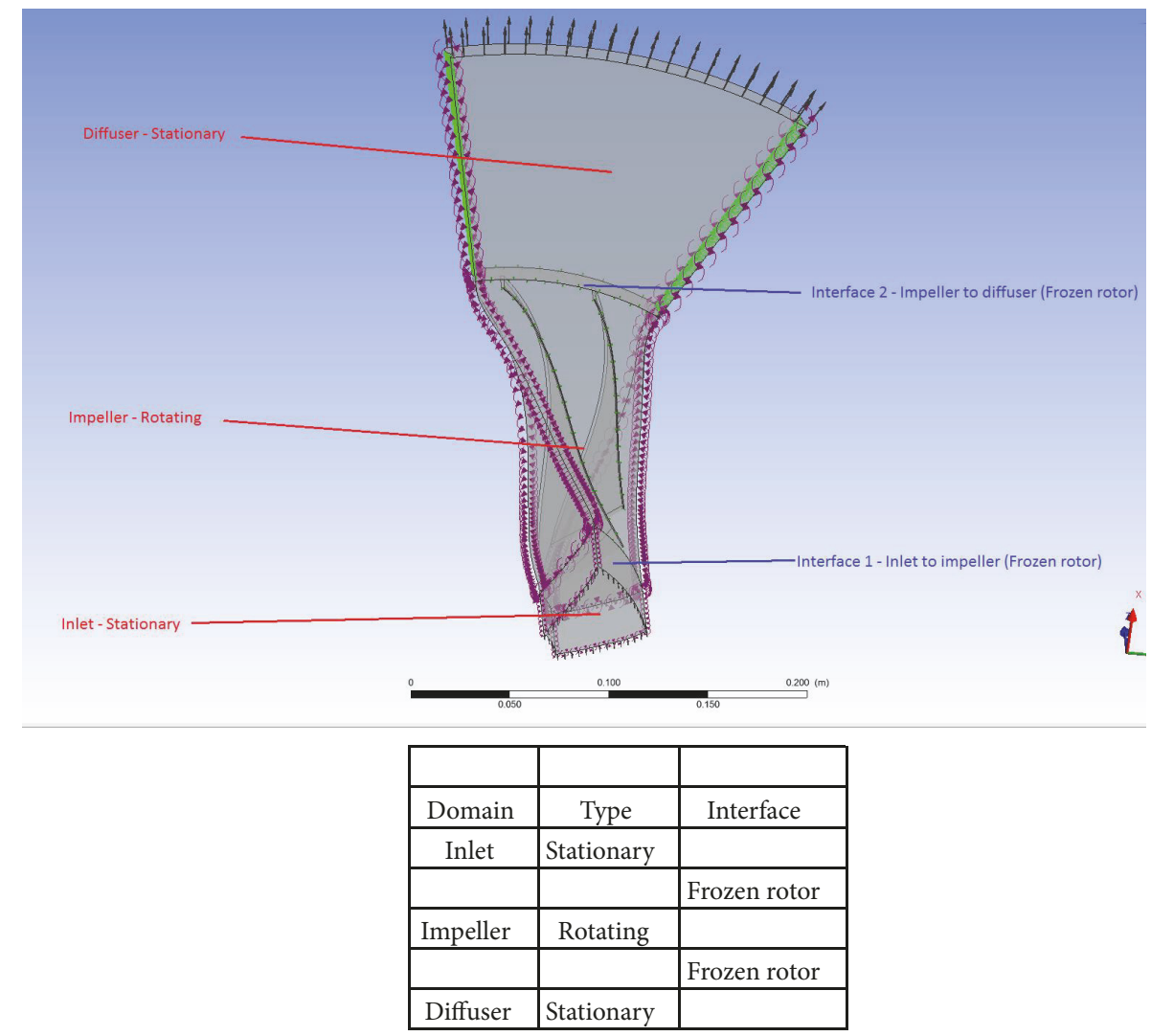

FIgURE 5: Domain partition.

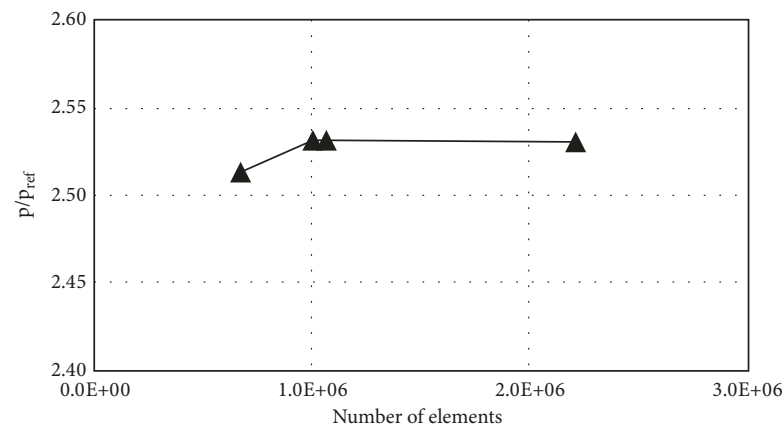

FiguRE 6: Mesh convergence.

to the experimental data. It is interesting to note that these differences are smallest, $2 \%$ or less, at the design speed and mass flow rate (461 Hz and $1.8 \mathrm{~kg} / \mathrm{s}$ ) or close to them (461 $\mathrm{Hz}$ and $1.98 \mathrm{~kg} / \mathrm{s}$ ). Further from the design operating point the errors are larger in the range of $2 \%$ to just over $5 \%$. This can be seen in Figure 9 which shows the average error for $\mathrm{r} / \mathrm{r}_{2}>1.2$ plotted against the distance from the design point calculated as $\sqrt{\left(\Delta N / N_{0}\right)^{2}+\left(\Delta q_{m} / q_{m o}\right)^{2}}$, where $N_{0}$ and $q_{m o}$ are the design point speed and mass flow rate, respectively, and the $\Delta$ quantities represent the difference from the design point. Although there is not a strong correlation between the data and the linear best-fit, suggesting that the relative

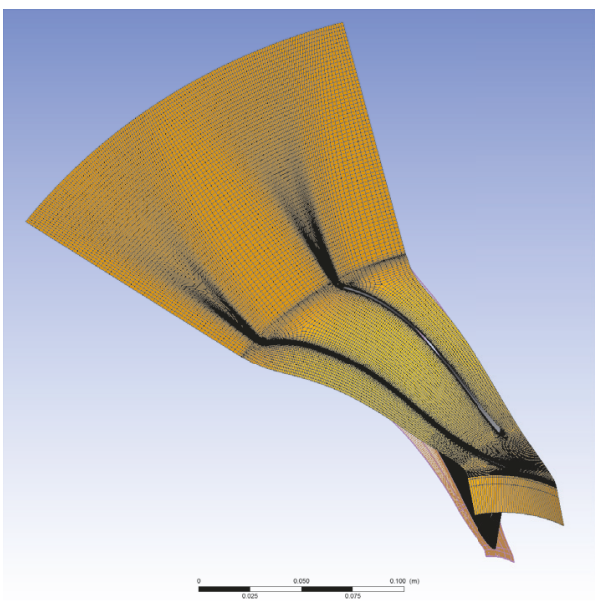

FIgURE 7: Simulation grid.

importance of $\Delta N / N_{0}$ and $\Delta q_{m} / q_{m o}$ may not be equal in determining the accuracy of the simulations, there is a clear trend for the simulations to be more accurate close to the design point. One factor affecting this is the volute. In the experiments there is a volute, which is developed to provide a uniform circumferential pressure distribution at the design operating point. At off-design conditions the circumferential pressure distribution is not uniform. At mass flows lower 

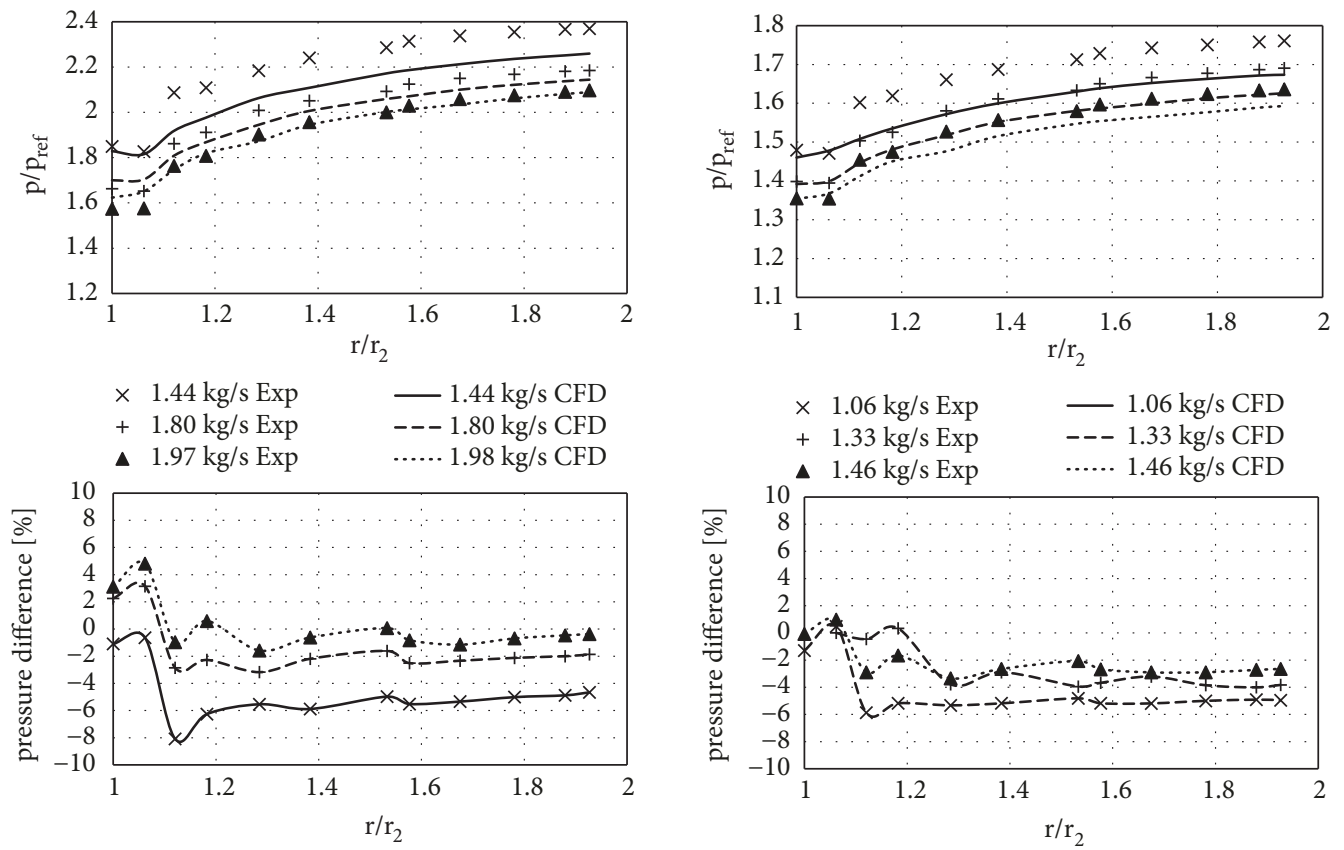

$* 1.44 \mathrm{~kg} / \mathrm{s}$
$-+-1.80 \mathrm{~kg} / \mathrm{s}$
$-\cdots \cdot 1.98 \mathrm{~kg} / \mathrm{s}$

$* 1.06 \mathrm{~kg} / \mathrm{s}$ $-+-1.33 \mathrm{~kg} / \mathrm{s}$

-... $1.46 \mathrm{~kg} / \mathrm{s}$

$461 \mathrm{~Hz}$

$369 \mathrm{~Hz}$

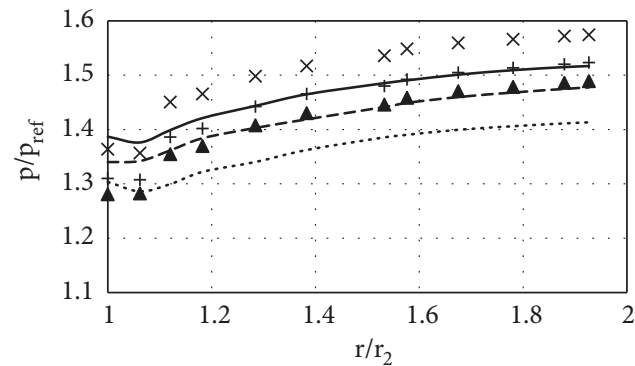
$\times 0.90 \mathrm{~kg} / \mathrm{s} \operatorname{Exp}$
$-0.90 \mathrm{~kg} / \mathrm{s}$ CFD
$+1.13 \mathrm{~kg} / \mathrm{s} \operatorname{Exp}$
--- $1.13 \mathrm{~kg} / \mathrm{s}$ CFD
\ $1.24 \mathrm{~kg} / \mathrm{s} \mathrm{Exp}$
…. $1.24 \mathrm{~kg} / \mathrm{s}$ CFD

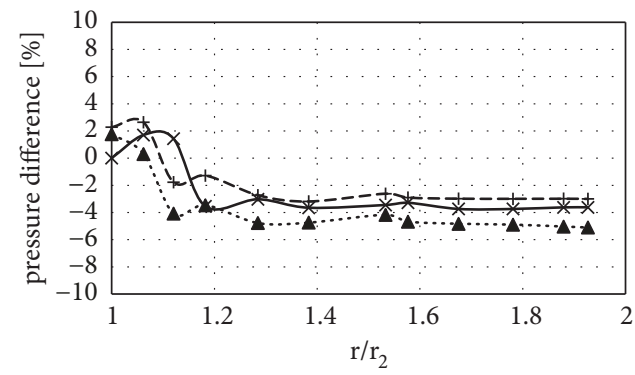

$$
\begin{array}{r}
* 0.90 \mathrm{~kg} / \mathrm{s} \\
-+-1.13 \mathrm{~kg} / \mathrm{s} \\
-\bullet \cdots 1.24 \mathrm{~kg} / \mathrm{s}
\end{array}
$$

$323 \mathrm{~Hz}$

FIGURE 8: Comparison of experimental and simulated pressure ratios. 
than the design flow, the pressure increases in the direction of rotation while at higher flows it decreases in the direction of rotation $[26,27]$. In the simulations there is a uniform boundary condition which is applied equally at all operating points. This difference can partially explain why inaccuracy is observed to increases the further we go from the design operating point.

In the region closer to the tips $\left(r / r_{2}<1.2\right)$ the difference varies more and the maximum differences $(+6 \%$ and $-8 \%)$ occur. This is to be expected due to the more rapid and less uniform variation in the pressure ratio is in this region. It is also interesting to note that in the inner region the differences are either positive (CFD overestimating the pressure ratio) or less negative (CFD underestimating the presser ratio by less) than in the outer region.

Other than this there is no clear trend in the data. For example, although the lowest mass flow rates flows all show the maximum difference of approximately $-6 \%$ in the outer region for the higher speeds, this behavior is not replicated by $323 \mathrm{~Hz}$ results. This suggest that other than the results being more accurate close to the design point as described above, there is no systematic error featuring in either set of results.

In Figure 8, the experimental error in the pressure ratio measurements (0.012) is approximately equal to the size of the symbols at 323 and $369 \mathrm{~Hz}$ and roughly half the symbol size at $461 \mathrm{~Hz}$, while the discretization error in the simulated pressure ratio is less than 0.002 . The differences observed between the CFD and the experimental measurements are somewhat larger than these errors. This can be due to features of the simulation, such as using a RANS approach with its associated turbulence model, which are not captured by the discretization error, as well small artefacts of a real compressor which are not included in the model used for CFD simulation. For example, the simulated compressor is perfectly symmetric, whereas the manufacturing and installation process for the real compressor will introduce a small level of asymmetry which, in areas such as the blade clearance, can impact on the performance [3].

4.2. CFD Pressure Line Variation. When comparing experimental and numerical results there is often an ambiguity as to where in the computational domain the inlet to outlet pressure line is taken in a spanwise sense. The experimental setup used had the first nine pressure taps placed into the diffuser shroud and as such represents a physical value $b / b_{2}$ of close to unity. Figure 10 compares the simulated pressure at different spanwise positions with the measured pressure close to $r / r_{2}=1$ for a selected operating condition. At higher values of $r / r_{2}$ there was no significant difference between the results for different spanwise positions. Closer agreement to the experimental results is shown at increased spanwise positions. In particular, it is noted that for spanwise values of 0.5 or less there seems to be an inversion of the pressure trend immediately downstream of the impeller-diffuser interface.

A key and interesting feature of the results is the initial drop in pressure immediately downstream of the impeller. This can be explained by the pinched diffuser with the pinch as $r / r_{2}=1.02$, as indicated in Figure 11, where $b$ is the diffuser

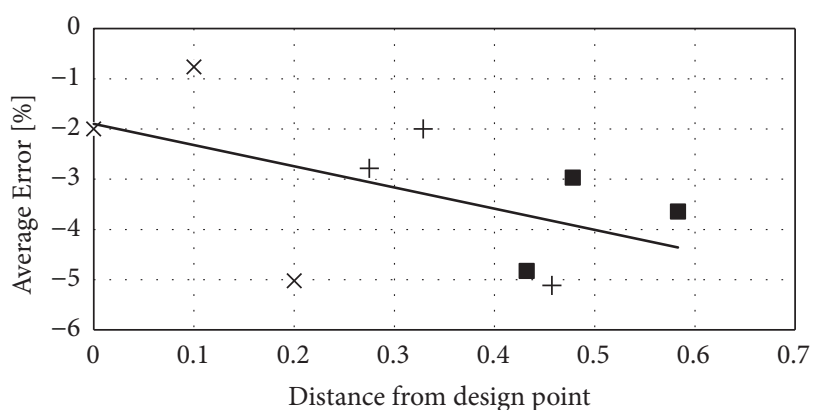

$$
\begin{array}{r}
\times 461 \mathrm{~Hz} \\
+369 \mathrm{~Hz} \\
\text { - } 323 \mathrm{~Hz}
\end{array}
$$

FIGURE 9: Variation in the average error for $r / r_{2}<1.2$ with the deviation from the design point.

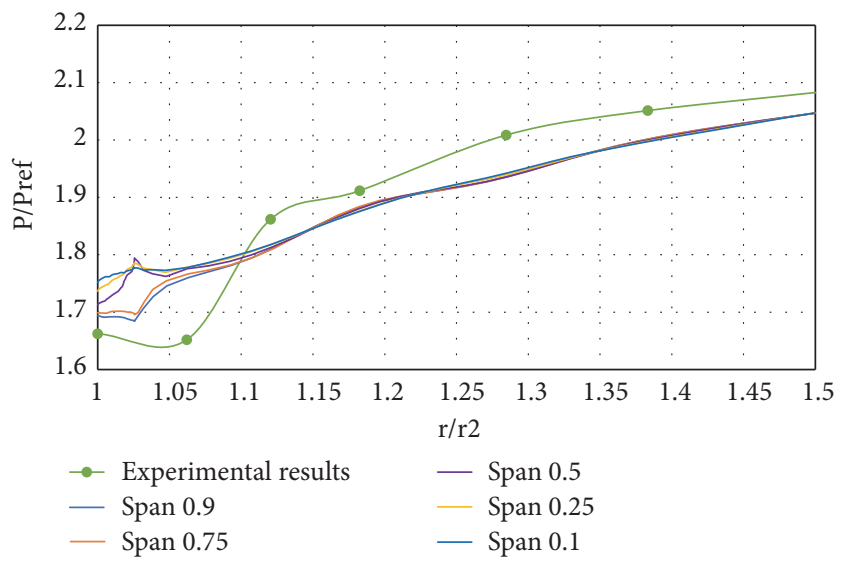

FIgURE 10: Pressure distribution at different spanwise positions at $461 \mathrm{~Hz}$ for a mass flow rate of $1.8 \mathrm{~kg} / \mathrm{s}$.

radius and $b_{2}$ is the radius at the impeller exit. The initial reduction in pressure in Figure 10 can be explained by the flow acceleration due to the pinched diffuser. Due to the resolution of the experimental results in Figure 10, it is not possible to determine a detailed picture of the pressure variation in this region; however, there is a measured decrease in pressure between the first two pressure taps. In the simulation results the pressure shows a small decrease in pressure in the $1<$ $\mathrm{r} / \mathrm{r}_{2}<1.02$ prior to the expected increase in the remainder of the diffuser, for the spanwise positions greater than 0.75 .

4.3. Impeller-Diffuser Interface. Physically speaking the interface between the impeller and the diffuser occurs at $\mathrm{r} / \mathrm{r}_{2}=1$. However, for modelling and meshing reasons the interface is typically placed a small distance downstream, for example, 1.025 in [12]; moreover there will be a small distance where the flow is still bound to the blade due to viscous effects. This means that the motion of the blade is still directly affecting the fluid in a small region beyond the geometrical extend of the blade. If the interface is placed too close to the blade tip then the standard meshing topology will attempt to create mesh cells stretching around and over the blade, 
leading to unacceptable mesh skewness. The effect of this interface placement was investigated and the results shown in Figure 12 at a spanwise distance of $0.9,461 \mathrm{~Hz}$, and $1.8 \mathrm{~kg} / \mathrm{s}$ mass flow rate. The results confirm the trend of increasing accuracy the closer to the impeller exit the interface is placed in [12]. A certain gap has to be left in order to avoid meshing issues. In the simulations presented in Figure $8 \mathrm{r} / \mathrm{r}_{2}=1.02$ was used.

Figure 12 shows that for the interface radii ratio value of 1.02 the pressure remains largely constant from pressure tap 1 to 2 . This correlates with the experimental data. For interface radii ratio values above 1.02 this effect is not evident. When a mixing reference frame approach is used for an interface radii ratio value of 1.02 the pressure is seen to increase from pressure tap 1 to 2 . This is due to the mixing reference frame averaging quantities across the mesh immediately up and down stream of the interface.

\subsection{Pressure and Velocity Profiles in the Impeller Region.} Having verified the accuracy of the computational model throughout the diffuser domain, the full pressure and velocity fields are studied in more detail in the diffuser and impeller regions. This is shown in Figures 13, 14, and 15 for the three speeds of $461 \mathrm{~Hz}, 368 \mathrm{~Hz}$, and $322 \mathrm{~Hz}$, respectively, for the nine operating conditions previously considered. In each of the three figures the static pressure is shown on the lefthand side and the velocity magnitude on the right-hand side and the mass flow rate increases from top to bottom. The impeller/diffuser boundary was set at $r / r_{2}=1.02$ and the results are shown at a spanwise position of 0.9. Since a frozen rotor model was applied in the simulations, the images in the figures represent a snapshot of a flow field in the diffuser.

The static pressure contours show that the pressure ratio decreases with mass flow rate and increases with rotational speed, as previously observed in Figure 3. Additionally, they also give details of the pressure variation through the impeller region and details of the pressure difference between the pressure and the suction sides of the blades. In Figures 13(a) and 13(c) the contour lines approximately join at the blades indicating a pressure difference equal to the width of the contour band. This appears to be consistent along the length of each blade and is the same for the main blade and the splitter blade. In Figure 13(e) the contours are close to joining at the blades but have a small offset indicating a small increase in the pressure difference across the blades at the highest mass flow rate. Figures 14 and 15 also show a pressure difference across the blades which decreases with the rotational speed.

When comparing the velocity magnitude contours a velocity jump across the frozen rotor interface can be observed. This view highlights the essential difference between the frozen rotor and mixing reference frame. Velocity "peaks" can be seen in the diffuser domain to be moving radially outwards and in the direction of rotation. If the diffuser were vanned this nonuniformity would be problematic; however as the diffuser is vaneless this is insignificant. In the impeller domain velocity contours show a "dead" spots of the Coriolis vortices, approximately $1 / 3$ of the way through the

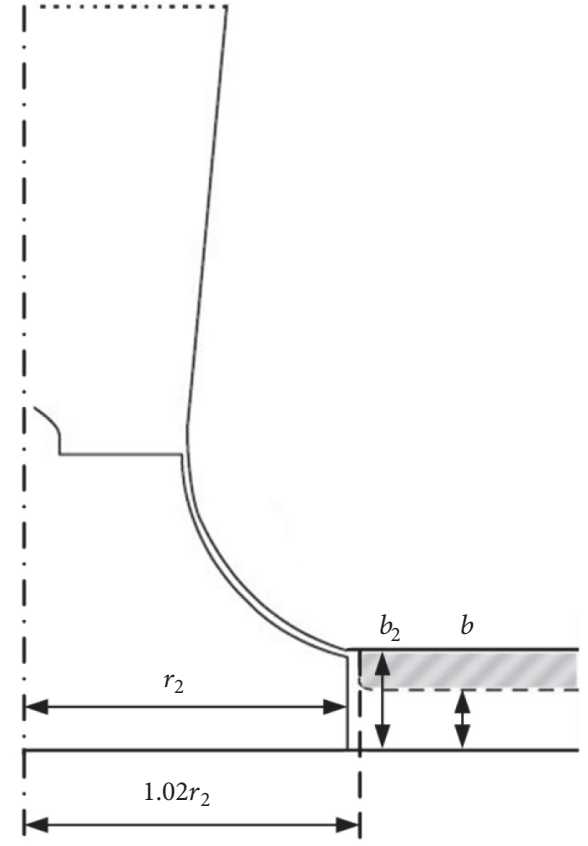

FIGURE 11: Details of the pinched diffuser.

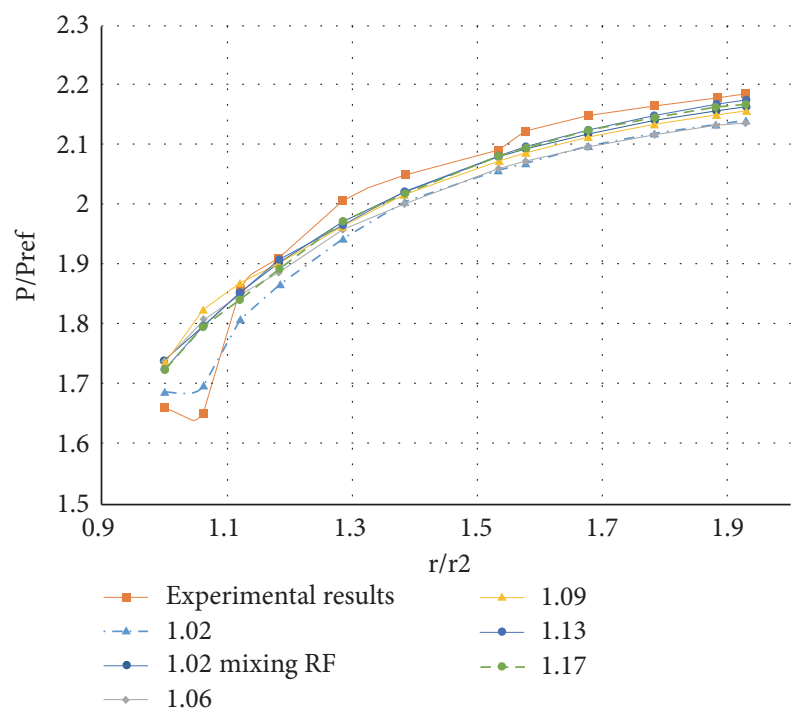

FIGURE 12: Domain interface position pressure distribution at a spanwise distance of $0.9,461 \mathrm{~Hz}$, and $1.8 \mathrm{~kg} / \mathrm{s}$ mass flow rate.

impeller domain. These are present at each of the rotation speeds. At the moderate and higher mass flow rates these vortices are relatively small and positioned slightly closer to the pressure side of the blades. At the lowest mass flow rate, for each rotation speed, the regions are significantly larger. At $461 \mathrm{~Hz}$ the region extends up to the splitter blade and at the lower speeds it virtually encloses the lower third of the splitter blade. 

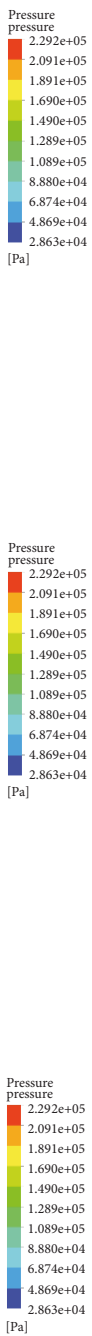

(c) Static pressure $(1.8 \mathrm{~kg} / \mathrm{s})$

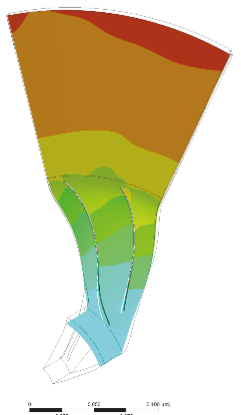

(e) Static pressure $(1.98 \mathrm{~kg} / \mathrm{s})$

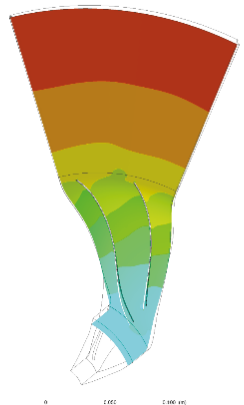

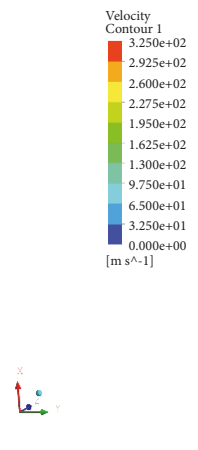

(a) Static pressure $(1.44 \mathrm{~kg} / \mathrm{s})$

FIGURE 13: Static pressure and velocity magnitude contours at $461 \mathrm{~Hz}$. $\stackrel{2.0}{\longrightarrow}$

(b) Velocity magnitude $(1.44 \mathrm{~kg} / \mathrm{s})$

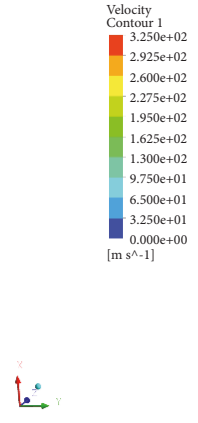

(d) Velocity magnitude $(1.8 \mathrm{~kg} / \mathrm{s})$

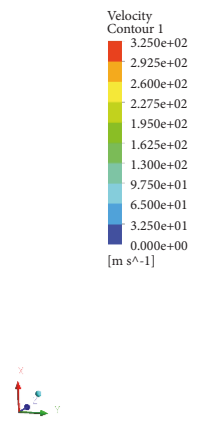

(f) Velocity magnitude $(1.98 \mathrm{~kg} / \mathrm{s})$ $\stackrel{0}{0}$<smiles>[AlH2]</smiles>

\section{Conclusion}

Experimental and numerical approaches have been applied to analyse the performance of a centrifugal compressor.

In general, the CFD model showed good agreement with the experimental measurements throughout the diffuser region. A maximum difference of $8 \%$ was observed in one simulation in the region close to the tip $\left(r / r_{2}<1.2\right)$, where the pressure variation with radial position tends to be less regular and increases at its maximum rate. Outside this region the magnitude of the differences was less and approximately constant with radial distance. Generally, the CFD underpredicted the pressure ratio, except for a few points close to the blade tips for some simulations. In particular, it was observed that, in this outer region, the accuracy of the simulation results was particularly good close to the design point of the compressor where the difference between the experimental and the CFD results was less than $2 \%$. Further from the design point the errors were larger but still less than approximately $5 \%$. No systematic differences were noticed within the range of parameters considered, validating the use of the model.

Typically, when compressors are modelled with CFD for design or research purposes, only a single blade passage is modelled with the assumption of circumferential uniformity, and the volute is omitted, as was done here. The results indicate that the inaccuracy of the simulations increase the further from the design operating conditions the performance is predicted. As the off-design operations 

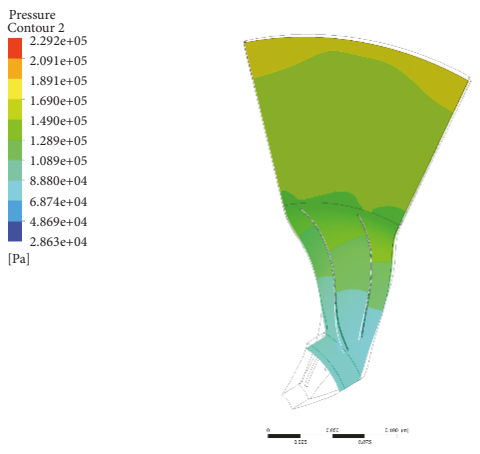

(a) Static pressure $(1.06 \mathrm{~kg} / \mathrm{s})$
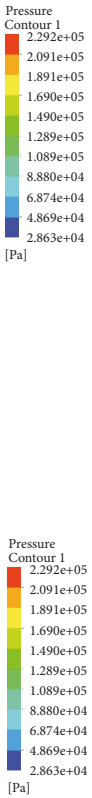

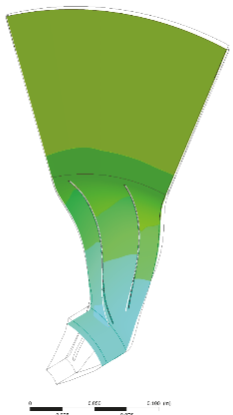

(c) Static pressure $(1.33 \mathrm{~kg} / \mathrm{s})$

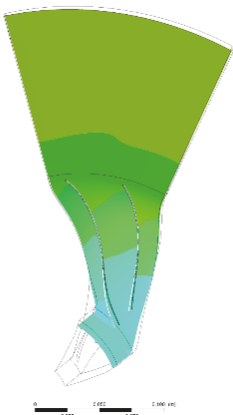

(e) Static pressure $(1.46 \mathrm{~kg} / \mathrm{s})$

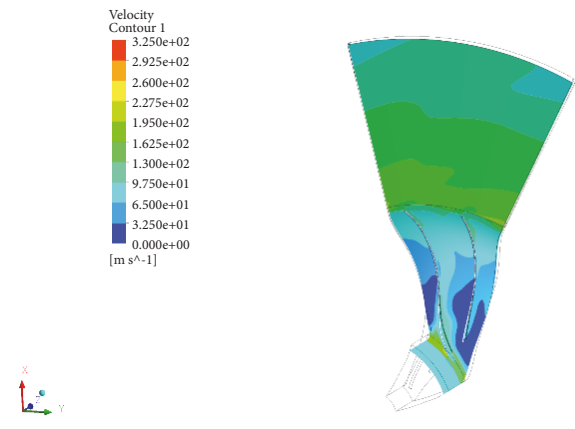

(b) Velocity magnitude $(1.06 \mathrm{~kg} / \mathrm{s})$

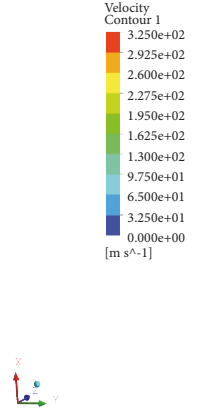

(d) Velocity magnitude $(1.33 \mathrm{~kg} / \mathrm{s})$

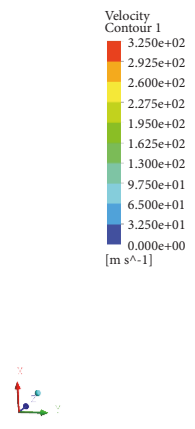

(f) Velocity magnitude $(1.46 \mathrm{~kg} / \mathrm{s})$
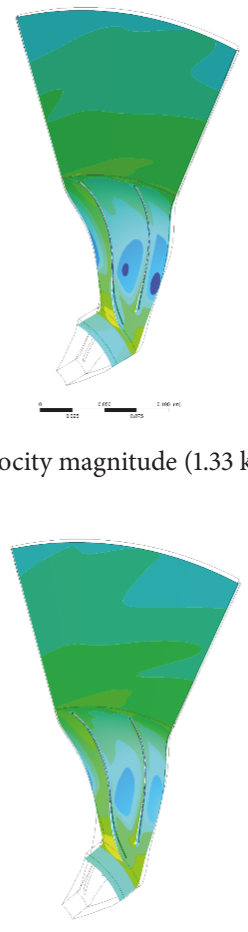

$-\cdots$ to.

to

k:

FIGURE 14: Static pressure and velocity magnitude contours at $368 \mathrm{~Hz}$. of compressors are becoming more important, the design engineers should bear this in mind. Works such as [28] allow for reasonable predictions of the effect of the volute, provided it decelerates the flow in an approximately adiabatic fashion.

The conventional CFD practice of placing the diffuser domain interface as close to the blade tips as possible produces the most accurate results for regions close to the blade tips but under predicts the static pressure at the diffuser outlet. Conversely increasing the $\mathrm{r} / \mathrm{r}_{2}$ position of the diffuser domain interface produces less accurate results near the blade tips but replicates the static pressure at the diffuser outlet more accurately. The variation in pressure in the spanwise direction through the diffuser was also considered. For $\mathrm{r} / \mathrm{r}_{2}>1.1$ no significant variation was observed with the spanwise position; however, close to the impeller outlet a small but significant difference was observed. For spanwise positions greater than $0.5 \mathrm{a}$ dip in the pressure was observed which was consistent with the experimental results (taken at the shroud with a spanwise position of approximately 1). This was not observed for spanwise positions of 0.5 or lower.

Contour plots were also presented which gave a detailed description of the velocity and pressure field through both the impeller and the diffuser region for the nine operating conditions considered.

Having validated a computational model more elaborate and detailed analysis can be undertaken with an increased degree of confidence, such as, for example, blade loading, flow 

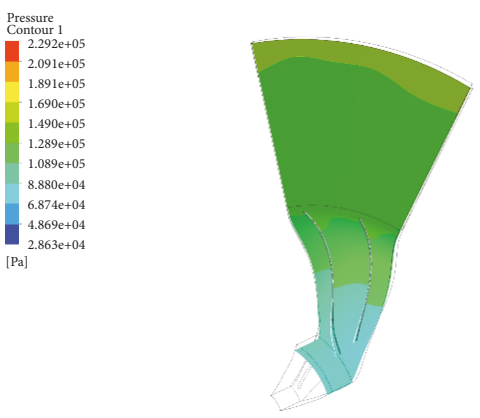

(a) Static pressure $(0.9 \mathrm{~kg} / \mathrm{s})$
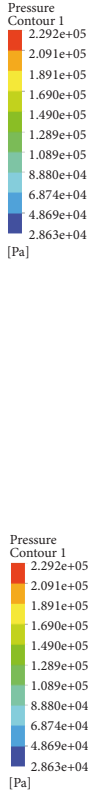

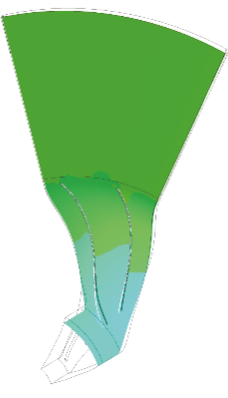

(c) Static pressure $(1.13 \mathrm{~kg} / \mathrm{s})$

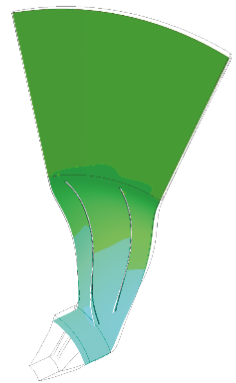

$-\ldots$

(e) Static pressure $(1.24 \mathrm{~kg} / \mathrm{s})$

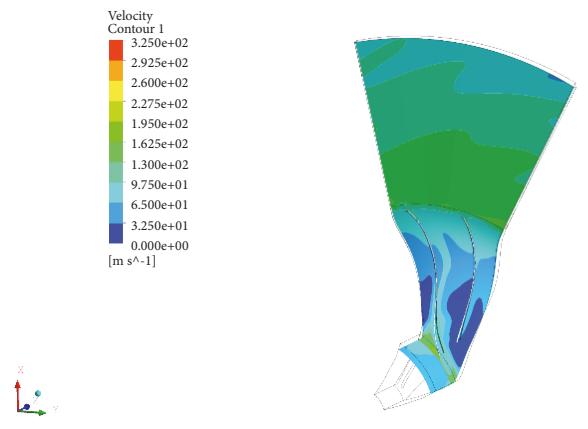

(b) Velocity magnitude $(0.9 \mathrm{~kg} / \mathrm{s})$

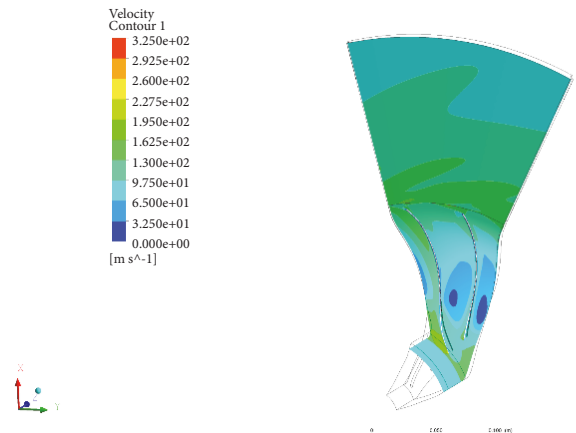

(d) Velocity magnitude $(1.13 \mathrm{~kg} / \mathrm{s})$

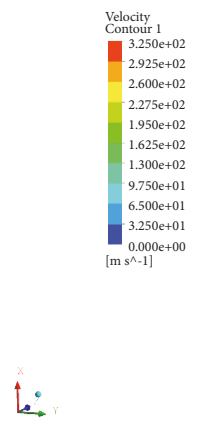

(f) Velocity magnitude $(1.24 \mathrm{~kg} / \mathrm{s})$
L.

t:

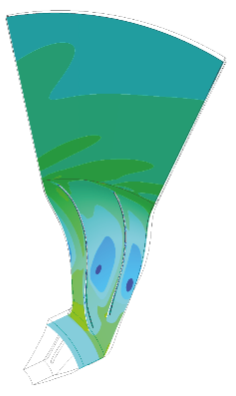

t:

FIGURE 15: Static pressure and velocity magnitude contours at $322 \mathrm{~Hz}$.

contours, and examining the flow as it approaches surge and choke.

\section{Data Availability}

Experimental data collected at LUT was used.

\section{Conflicts of Interest}

The authors declare that there are no conflicts of interest regarding the publication of this paper.

\section{Acknowledgments}

Numerical computations were done on the Sciama High Performance Compute (HPC) cluster which is supported by the ICG, SEPNet, and the University of Portsmouth. Brett Dewar, Mike Creamer, Mariana Dotcheva, Jovana Radulovic, and James M. Buick wish to thank InnovateUK for financial support provided for this work through the KTP grant [KTP009973].

\section{References}

[1] A. Broatch, J. Galindo, R. Navarro, and J. García-Tíscar, "Methodology for experimental validation of a CFD model for predicting noise generation in centrifugal compressors," International Journal of Heat and Fluid Flow, vol. 50, pp. 134144,2014

[2] J. Galindo, A. Tiseira, R. Navarro, and M. López, "Influence of tip clearance on flow behavior and noise generation of 
centrifugal compressors in near-surge conditions," International Journal of Heat and Fluid Flow, vol. 52, pp. 129-139, 2015.

[3] C. Xu and R. S. Amano, "Effects of Asymmetric Radial Clearance on Performance of a Centrifugal Compressor," Journal of Energy Resource Technology, vol. 140, no. 5, Article ID 052003, 16 pages, 2017.

[4] X. Q. Zheng, J. Huenteler, M. Y. Yang, Y. J. Zhang, and T. Bamba, "Influence of the volute on the flow in a centrifugal compressor of a high-pressure ratio turbocharger," Proceedings of the Institution of Mechanical Engineers, Part A: Journal of Power and Energy, vol. 224, no. 8, pp. 1157-1169, 2010.

[5] S. R. Konakala and M. Govardhan, "CFD studies on the performance of a centrifugal compressor with single wall rotating vaneless diffusers at the wall extension ratios of 1.1 and 1.15," in Proceedings of the ASME 2017 Gas Turbine India Conference, GTINDIA 2017, Bangalore, India, December 2017.

[6] E. Rinaldi, R. Pecnik, and P. Colonna, "Computational fluid dynamic simulation of a supercritical $\mathrm{CO}_{2}$ compressor performance map," Journal of Engineering for Gas Turbines and Power, vol. 137, Article ID 072602, 7 pages, 2015.

[7] J. Li, Y. Yin, S. Li, and J. Zhang, "Numerical simulation investigation on centrifugal compressor performance of turbocharger," Journal of Mechanical Science and Technology, vol. 27, no. 6, pp. 1597-1601, 2013.

[8] R. Hadavandi, F. Fontaneto, and J. Desset, "Complete characterization of a highly loaded low pressure compressor at different reynolds numbers for computational fluid dynamics simulations," Journal of Turbomachinery, vol. 140, no. 6, p. 061008, 2018.

[9] J. Schreiber, X. Ottavy, G. Ngo Boum, S. Aubert, and F. Sicot, "Numerical simulation of the flow field in a high speed multistage compressor: study of the time discretization sensitivity," in Proceedings of the ASME Turbo Expo 2015: Turbine Technical Conference and Exposition, p. V02BT39A006, Montreal, Quebec, Canada, 2015.

[10] C. Xu and M. Muller, "The development of high performance centrifugal compressor using CFD and other considerations," in Proceedings of the ASME 2017 Power Conference Joint With ICOPE-17 collocated with the ASME 2017 11th International Conference on Energy Sustainability, the ASME 2017 15th International Conference on Fuel Cell Science, Engineering and Technology, and the ASME 2017 Nuclear Forum, Charlotte, Calif, USA, 2017.

[11] L. Gibson, L. Galloway, S. I. Kim, and S. Spence, "Assessment of turbulence model predictions for a centrifugal compressor simulation," Journal of the Global Power and Propulsion Society, vol. 1, pp. 142-256, 2017.

[12] S. R. Shah, S. V. Jain, R. N. Patel, and V. J. Lakhera, "CFD for centrifugal pumps: a review of the state of the art," Procedia Engineering, vol. 51, pp. 715-720, 2013.

[13] S. Anish and N. Sitaram, "Computational investigation of impeller-diffuser interaction in a centrifugal compressor with different types of diffusers," Proceedings of the Institution of Mechanical Engineers, Part A: Journal of Power and Energy, vol. 223, no. 2, pp. 167-178, 2008.

[14] P. Röyttä, A. Grönman, A. Jaatinen, T. Turunen-Saaresti, and J. Backman, "Effects of different blade angle distributions on centrifugal compressor performance," International Journal of Rotating Machinery, vol. 2009, Article ID 537802, 9 pages, 2009.
[15] G. Kergourlay, M. Younsi, F. Bakir, and R. Rey, "Influence of splitter blades on the flow field of a centrifugal pump:testanalysis comparison," International Journal of Rotating Machinery, vol. 2007, Article ID 85024, 13 pages, 2007.

[16] S. Marelli, C. Carraro, G. Marmorato, G. Zamboni, and M. Capobianco, "Experimental analysis on the performance of a turbocharger compressor in the unstable operating region and close to the surge limit," Experimental Thermal \& Fluid Science, vol. 53, no. 2, pp. 154-160, 2014.

[17] Z. Liu and D. Hill, "Issues surrounding multiple frames of reference models for turbo compressor applications," in Proceedings of the International Compressor Engineering Conference, 2000.

[18] A. Zamiri, B. J. Lee, and J. Taek Chung, "Numerical evaluation of transient flow characteristics in a transonic centrifugal compressor with vaned diffuser," Aerospace Science and Technology, vol. 70, pp. 244-256, 2017.

[19] A. Jaatinen-Värri, J. Tiainen, T. Turunen-Saaresti et al., "Centrifugal compressor tip clearance and impeller flow," Journal of Mechanical Science and Technology, vol. 30, no. 11, pp. 50295040, 2016.

[20] F. R. Menter, "Review of the shear-stress transport turbulence model experience from an industrial perspective," International Journal of Computational Fluid Dynamics, vol. 23, no. 4, pp. 305-316, 2009.

[21] Z. Liu and D. L. Hill, "Issues surrounding multiple frames of reference models for turbo compressor applications," in International Compressor Engineering Conference, p. 1369, 2000.

[22] A. Jaatinen-Värri, A. Grönman, T. Turunen-Saaresti, and J. Backman, "Investigation of the stage performance and flow fields in a centrifugal compressor with a vaneless diffuser," International Journal of Rotating Machinery, vol. 2014, Article ID 139153, 10 pages, 2014.

[23] T. Turunen-Saaresti, A. Reunanen, and J. Larjola, "Computational and experimental study of pinch on the performance of a vaneless diffuser in a centrifugal compressor," Journal of Thermal Science, vol. 15, no. 4, pp. 306-313, 2006.

[24] P. E. Smirnov, T. Hansen, and F. R. Menter, "Numerical simulation of turbulent flows in centrifugal compressor stages with different radial gaps," in Proceedings of the ASME Turbo Expo 2007: Power for Land, Sea, and Air, Montreal, Canada, 2007.

[25] I. B. Celik, U. Ghia, P. J. Roache, C. J. Freitas, H. Coleman, and P. E. Raad, "Procedure for estimation and reporting of uncertainty due to discretization in CFD applications," Journal of Fluids Engineering, vol. 130, no. 7, pp. 0780011-0780014, 2008.

[26] S. Shaaban and J. Seume, "Aerondynamic performance of small turbocharger compressor," in Proceedings of the ASME Turbo Expo 2007: Power for Land, Sea, and Air, pp. GT2007-27558, Montreal, Canada, 2007.

[27] A. Jaatinen, A. Grönman, and T. Turunen-Saaresti, "Effect of diffuser width and tip clearance on the static pressure distributions in a vaneless diffuser of a high-speed centrifugal compressor," in Proceedings of the 10th International Conference on Turbochargers and Turbocharging, pp. 319-324, London, UK, May 2012.

[28] D. Hagelstein, K. Hillewaert, R. A. Van den Braembussche, A. Engeda, R. Keiper, and M. Rautenberg, "Experimental and numerical investigation of the flow in a centrifugal compressor volute," in Proceedings of the ASME 1999 International Gas Turbine and Aeroengine Congress and Exhibition, Indianapolis, Ind, USA, 1999. 


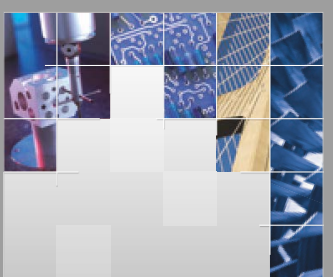

\section{Enfincering}
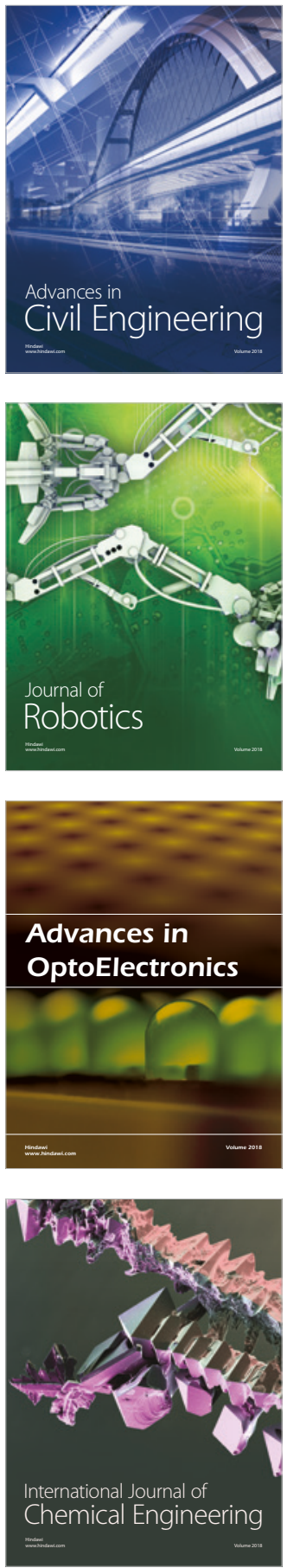

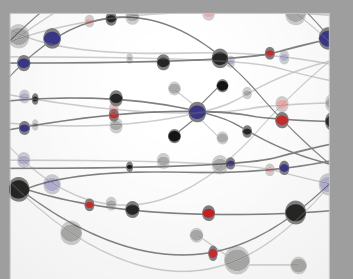

\section{Rotating \\ Machinery}

The Scientific World Journal

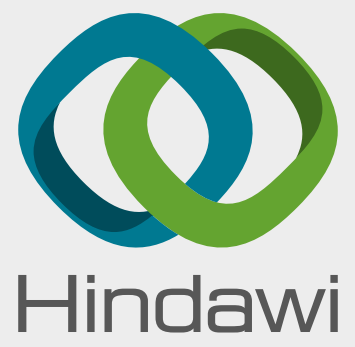

Submit your manuscripts at

www.hindawi.com
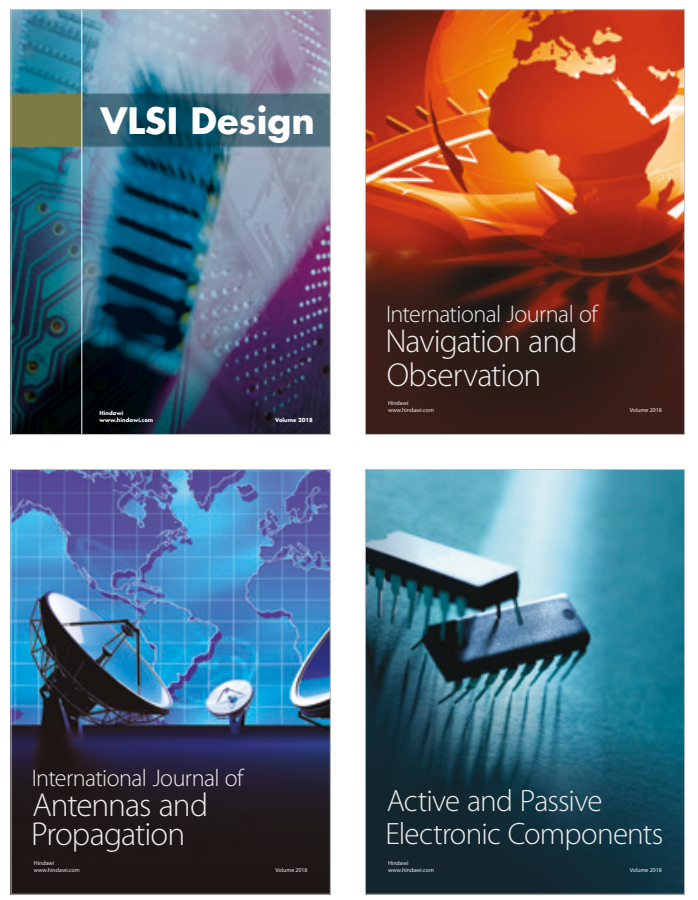
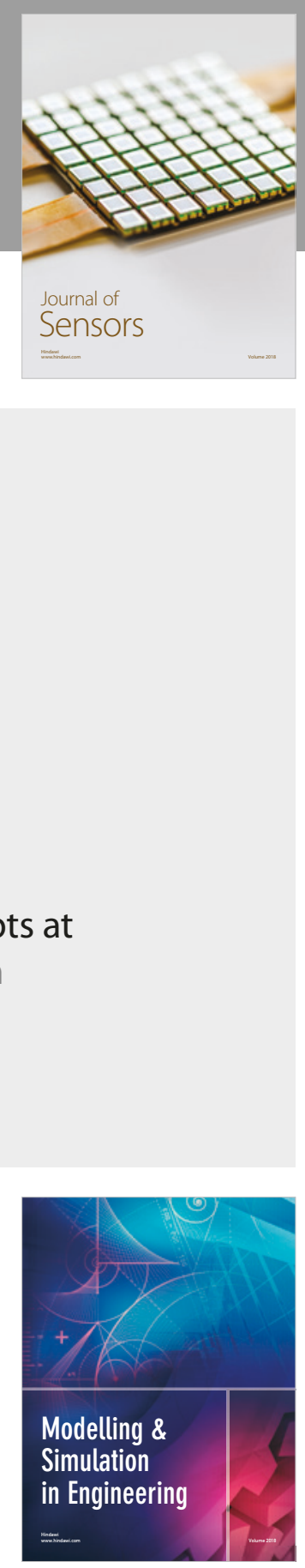

\section{Advances \\ Multimedia}
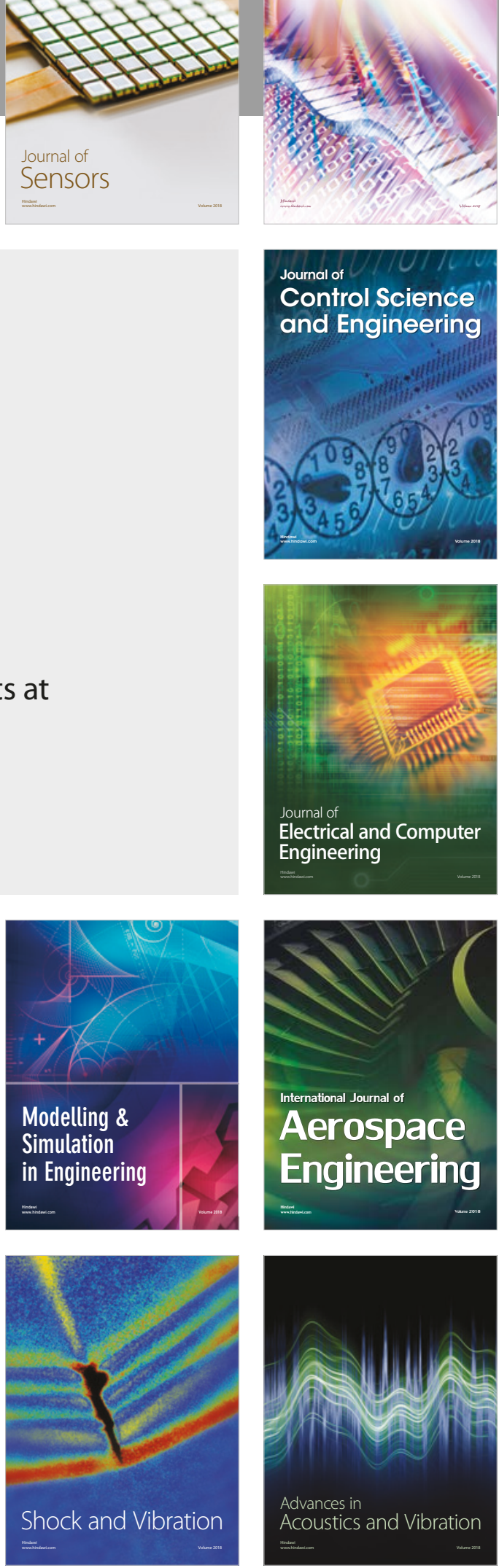